\title{
Research
}

\section{Plasmodium falciparum malaria in children at a tertiary teaching hospital: ABO blood group is a risk factor}

\author{
John Teye Kuadzi ${ }^{1, \&}$, George Ankra-Badu², Mark Michael Addae ${ }^{1}$ \\ ${ }^{1}$ Department of Medical Laboratory Sciences, School of Allied Health Sciences, Korle-Bu, Accra, Ghana, ${ }^{2}$ Department of Haematology, University of \\ Ghana Medical School, Korle-Bu, Accra, Ghana
}

${ }^{\&}$ Corresponding author: John Teye Kuadzi, Department of Medical Laboratory Sciences, School of Allied Health Sciences, Korle-Bu, Accra, Ghana

Key words: ABO blood groups, malaria, severity, Plasmodium falciparum

Received: 15/05/2011 - Accepted: 02/09/2011 - Published: 06/09/2011

\begin{abstract}
Background: $\mathrm{ABO}$ blood group antigens are formed by terminal glycosylation of glycoproteins and glycolipid chains present on cell surfaces. Glycosylation modulates all kinds of cell-to-cell interactions and this may be relevant in malaria pathophysiology, in which adhesion has been increasingly implicated in disease severity. This study was done to determine the association between $\mathrm{ABO}$ phenotypes and the severity of $P$. falciparum malaria in children. Methods: One hundred and twenty one children were assessed at the Department of Child Health, KBTH from May to August 2008. ABO blood groups were determined by agglutination. The haemoglobin measurement was done with the haematology analyzer, Sysmex KX-21N. Malaria parasites were enumerated and the presence of malaria pigment noted. Identification of $P$. falciparum was done. Statistical tests used were odds ratio and chi square at a significance level of $p<0.05$. Results: $24.3 \%$ of the 121 children had severe falciparum malaria, and their mean haemoglobin was $4.49 \mathrm{~g} / \mathrm{dl}(S D \pm 1.69)$. No significant association was found between the $A B O$ phenotypes and malaria infection ( $p$ $>0.05$ ). Blood group $A$ was associated with more severe malaria as compared to the blood group $O$ individuals (Odds ratio $=0.79, p>0.05$ ); blood group $A B$ (Odds ratio $=0.14, p>0.05)$ and also there was a significant difference in severity of malaria between blood group $O$ and blood group $B($ Odds ratio $=1.28, p>0.05)$. Conclusion: Non-O blood group children are more prone to severe malaria caused by $P$. falciparum malaria than the group $\mathrm{O}$, despite the lack of significant association between $\mathrm{ABO}$ blood groups and falciparum malaria.
\end{abstract}

Pan African Medical Journal. 2011; 10:2

This article is available online at: http://www.panafrican-med-journal.com/content/article/10/2/full/

(c) John Teye Kuadzi et al. The Pan African Medical Journal - ISSN 1937-8688. This is an Open Access article distributed under the terms of the Creative Commons Attribution License (http://creativecommons.org/licenses/by/2.0), which permits unrestricted use, distribution, and reproduction in any medium, provided the original work is properly cited.

Pan African Medical Journal - ISSN: 1937- 8688 (www.panafrican-med-journal.com)

Published in partnership with the African Field Epidemiology Network (AFENET). (www.afenet.net) 
ABO blood groups are carbohydrate histo-blood antigens that are also expressed in many tissues and have important roles in modulating protein activities both in infection and in some types of cancer [1]. These antigens are formed by terminal glycosylation of glycoproteins and glycolipid chains present on cell surfaces. Glycosylation modulates all kinds of cell-to-cell interactions and this may be relevant in malaria pathophysiology, in which adhesion has been increasingly implicated in disease severity [2]. Blood group A has been reported as a risk factor for severe malaria [3], and as a co-receptor for $P$. falciparum resetting [4], whereas blood group $O$ may offer some protection against severity of disease [5]. There is increasing evidence that both the risk of acquiring $P$. falciparum infection, and the risk of developing severe complications are determined by host genetic factors [6]. The protective role of several erythrocytic variants, some of them related to blood groups, is one of the best examples of this genetic modulation [7]. The others include haemoglobins $S, C$ and $E$, a and $\beta$ thalassaemias, Glucose-6-phosphate dehydrogenase deficiency, Southern Asian Ovalocytosis, and Glycophorins A, B and C variants, all of which influence malaria pathogenesis [8].

Malaria is the most important parasitic infection of man, and is associated with a huge burden of morbidity and mortality in many parts of the tropical world. Mortality rates of $10-30 \%$ have been reported among children referred to hospitals with severe malaria, although these rates are even higher in rural and remote areas where diagnosis and treatment are not readily available [9]. Over 40\% of the world's children live in malaria-endemic countries. Each year, approximately 300 to 500 million malaria infections lead to over one million deaths, of which over $75 \%$ occur in African children under 5 years infected with $P$. falciparum [10]. Malaria accounts for one in five of all childhood deaths in Africa. Frequent consequences of malaria anaemia, low birth-weight, epilepsy, and neurological problems compromise the health and development of millions of children throughout the tropical world [11]. Severe and complicated malaria is usually caused by delay in treating an uncomplicated attack of $P$. falciparum [12].

\section{The immune system: parasite survival strategy and disease}

It is helpful to consider the multifaceted nature of the interaction between the host immune system and the parasite. Central to this interaction are cytokines that are released by immunocompetent cells in a highly regulated fashion [13]. They participate in the control of all immunologically relevant events, whether they concern either activation, proliferation, and subsequent effector functions of recirculating immunocompetent cells or regulation of cells residing in tissues (for example, resident mononuclear phagocytes and endothelial cells). It has been established that cytokines not only participate in the qualitative (for example, antibody isotype switch) and quantitative regulation of the immune response but also participate in many other complex processes such as hematopoiesis and pregnancy. During the erythrocytic cycle, soluble products of Plasmodium spp. known as malarial toxins direct systemic release of proinflammatory cytokines (for example, tumor necrosis factor-o (TNF-ix)) which act on many other cellular systems such as endothelium. Equally important are parasite antigens, which stimulate $\mathrm{T}$ cells to directly secrete or induce production of cytokines from other cells. Before $P$. falciparum infection, many individuals have $P$. falciparum reactive $\mathrm{T}$ cells, often at high frequency. Such parasite-reactive $\mathrm{T}$ cells have probably arisen as a result of antigenic cross reactivity between environmental organisms and parasite-derived molecules [14].

Incubation of blood mononuclear cells with parasitized erythrocytes can drive proliferation of these T cells even when the parasitaemia is as low as one parasite per microliter of blood. Because many of these T cells secrete interferon y (IFN-y) and other cytokines and can facilitate production of TNF-O $\sim$ by monocytes, they have the potential to be involved in disease pathogenesis. Both IFN- ${ }^{\sim}$ and TNF-Cl may play roles in dyserythropoietic anemia, and TNF-a may contribute to cerebral malaria as a result of up-regulation of intercellular adhesion molecule-1 (ICAM-1) in cerebral blood vessel endothelium. With respect to TNF-et production, T cells--whether they express y8 [15] or oil8 T cell receptors may play as important a role in disease pathogenesis as that postulated for the direct stimulation of mononuclear phagocytes by malarial toxins. It is likely that parasitedependent activation of $\mathrm{T}$ cells and mononuclear phagocytes leads not only to disease but also to killing of parasites. Whether all of the crossreactive $T$ cells, once activated during the primary infection, will remain functional during a persistent infection or until exposure to re-infection deserves to be studied. The parasite also has other strategies for interacting with the immune system, including the following: antigenic variation; (it) a still undefined, splenic dependent regulation of parasite genes encoding structural proteins and adhesive molecules on the erythrocyte surface that are involved in adherence to endothelium; and low immunogenicity, of conserved parasite peptides that are targets of antibodies able to interfere with parasite survival.

\section{Possible mechanisms to explain P. falciparum selective genetic pressure in favour of group 0 and against group $A$}

The adherence of parasitized RBCs to other cells is central to the pathophysiology of severe malaria syndromes including cerebral malaria, respiratory failure, multi-organ failure and death [16,17]. Parasitized RBCs adhere to the vasculature through a process termed "sequestration" closely mimicking inflammatory leukocyte attachment [18]. Furthermore, half of infected RBC isolates51 form occlusive intravascular aggregates, which consist not only of infected RBCs bound to each other ("autoagglutinates") [19], but also of infected RBCs bound to uninfected RBCs ("homotypic RBC rosettes") [20] and/or to platelets ("heterotypic RBC rosettes") [21]. Sequestration and rosette formation impair blood flow, causing tissue ischemia and cell death [22]. Not surprisingly, in-vitro rosetting is more pronounced in parasite strains derived from patients with severe disease, particularly in cases of cerebral malaria [23-26]. P. falciparum is unique among malaria species in that infected erythrocytes express an adhesive determinant, termed Plasmodium falciparum Erythrocyte Membrane Protein-1 (PfEMP-1). PfEMP-1 is encoded by the parasite genome and is expressed on the outer surface of infected RBCs. PfEMP-1 binds to a variety of target molecules found on RBCs, platelets, and vascular endothelial cells $[16,17]$. The structure of PfEMP-1 includes variable numbers of two types of adhesive binding domains: Duffy binding-like (DBL) regions and cysteine-rich interdomain regions (CIDR). DBL-1a demonstrates lectin-like properties, causing it to bind primarily to cells bearing A and B blood group oligosaccharides, and to other glycosylated targets, such as the glycoprotein CD35 (CR1), and heparan sulfate-like glycosaminoglycan [27,28]. CIDR1, on the other hand, binds principally to CD36 (Platelet Glycoprotein IV), thus targeting platelets and endothelium. 
It has been established that parasitized erythrocytes form rosettes more readily with red blood cells of $A, B$, or $A B$ groups than with cells of blood group O. This parasite-triggered RBC rosette formation is associated with severity of malaria disease [14]. Rosette formation and autoagglutination are adhesive phenotypes associated with disease severity in $P$. falciparum malaria [29]. The adherence of parasitized RBCs to other cells is central to the pathophysiology of severe malaria syndromes including cerebral malaria, respiratory failure, multi-organ failure and death $[16,17]$.

There is increasing evidence that $P$. falciparum malaria is influenced by ABO blood group but the extent of association between both is yet to be well defined. $P$. falciparum, the most dangerous or deadly of the four human malaria parasites, causes about $90 \%$ of all malaria deaths in the world today especially in sub-Saharan Africa $[9,20]$. However, no risk associated data for ABO phenotypes and $P$. falciparum malaria has been reported to date, in Ghana. Thus, this study investigated the hypothesis that ABO blood groups are associated with the severity of $P$. falciparum infection and the results showed that non-O blood group children are more prone to severe malaria caused by $P$. falciparum than the group $O$ children.

\section{Methods}

\section{Ethics}

This study was approved by the Ethics Review Committee of the School of Allied Health Sciences, College of Health Sciences; Korle-Bu. Parental/guardian consent for child participation was sought during the study.

\section{Study Site and Sample Size}

The study was carried out at the Department of Child Health, Korle-Bu Teaching Hospital (KBTH) from May to August 2008 . The KBTH is the largest tertiary hospital in Ghana with 17 departments and 1500 beds. One hundred and twenty one (121) children between 3 months and twelve years were sampled.

\section{Inclusion criteria}

Patient between 3 months and twelve years old, whose blood film (BF) test was reported as malaria parasites present and thin film showed Plasmodium specie to be falciparum.

\section{Exclusion criteria}

Patient below 3 months old or twelve years and above; whose blood film (BF) test was reported either as no malaria parasite present or malaria parasites present and thin film showed Plasmodium specie to be either falciparum or malariae.

\section{Blood collection and staining}

Two $\mathrm{ml}$ venous blood from the patient was collected into an EDTA-anticoagulated tube $(1.2 \mathrm{mg}$ of anhydrous dipotassium salt) using a $2 \mathrm{ml}$ syringe and needle set. Two drops of blood were placed on a clean glass slide and a thick film and a thin film were prepared on the same slide and allowed to air dry. The thin film was fixed with methanol for one minute. The slides were placed in a staining rack and immersed in a staining trough. Giemsa stain (Wako, Japan) diluted 1 in 10 with phosphate buffer pH 7.2 was used to stain the film for 10 minutes. The stain was washed off the slides using the buffer, $\mathrm{pH}$ 7.2. The back of the slides were wiped dry and placed in a draining rack for the film to air-dry.

\section{Microscopy and parasite density determination}

The parasite density was counted as parasite numbers per microlitre of blood by counting parasites against white blood cells. Using the $\mathrm{x} 100$ objective, 200 WBCs were counted systematically, estimating at the same time the numbers of parasites (asexual) in each field covered, with two tally counters.

Calculation $=$ WBC count $/ \mu \mathrm{l}$ of patient X Parasites counted against $200 \mathrm{WBCs} / 200$

The above formula was used if after 200 WBCs have been counted, and 10 or more parasites were identified. However, if after 200 WBCs have been counted, and 9 or fewer parasites have been counted, counting continued until 500 WBCs have been counted and the number of parasites was recorded.

\section{Severity of disease}

Severity of the Plasmodium falciparum malaria disease was determined based on the parasite density calculated as above. Severe parasitaemia: was defined as hyperparasitaemia (> 250,000 parasites/ $\mu$ l or more than $10 \%$ of red cells are parasitized); and/or severe anaemia (Haemoglobin concentration of $<5 \mathrm{~g} / \mathrm{dl}$ ). Moderate parasitaemia: was defined as parasitaemia between $51,000-249,000$ parasites/ $\mu$ l and/or Haemoglobin concentration between $5-8 \mathrm{~g} / \mathrm{dl}$. Mild parasitaemia: was defined as parasitaemia of 1,000 - 50,000 parasites/ $\mu$ l and/or Haemoglobin concentration $>8 \mathrm{~g} / \mathrm{dl}$. 


\section{ABO grouping}

The spun tube technique [30], a liquid-phase system, was employed for the detection of $A B O$ antigens and antibodies using cell and serum grouping. Four small tubes $(75 \times 12 \mathrm{~mm})$ were labeled 1 to 4 . Each tube was filled as follows:

Tube 1 - 1 volume anti-A serum and 1 volume $5 \%$ patient's red cell suspension in saline

Tube 2 - 1 volume anti-B serum and 1 volume $5 \%$ patient's red cell suspension in saline

Tube 3 - 1 volume patient's serum and 1 volume $5 \%$ A cells in saline

Tube 4 - 1 volume patient's serum and 1 volume $5 \%$ B cells in saline

The contents of the tubes were mixed by gently tapping the base of each tube with the finger. The tubes were left at room temperature for 5 minutes and then centrifuged at $150 \mathrm{~g}$ for a minute. The results were read by gently tapping the base of each tube, looking for agglutination or haemolysis. Red cell reagents (known A, B and O cells) were used to control the antisera (A and B). An autocontrol was also set i.e. patients red cells were added to their own serum to detect the possible presence of autoagglutination. The haemoglobin measurement and leucocyte count were done with an automated haematology analyzer, Sysmex KX-21N. The Sysmex KX-21N employs DC detection method for the leucocyte count and Non-cyanide Sodium Lauryl Sulfate (SLS) method for the haemoglobin measurement.

\section{Results}

The basic demographic data of the 121 children is presented in Table 1 . ABO phenotypes distribution was observed as A - 24 (19.8\%), B - 32 $(26.4 \%), A B-5(4.2 \%)$ and $O-60(49.6 \%)$ among the 121 children. Twenty-six $(24.3 \%)$, of the one hundred and twenty one (121) children assessed were diagnosed to have severe falciparum malaria (Table 2), who had a mean age of 2.2 years (SD \pm 1.8 ), mean leucocyte count of 11.5 \pm 4.5 and mean haemoglobin concentration of $4.5 \mathrm{~g} / \mathrm{dl}(\mathrm{SD} \pm 1.7)$ (Table 3$)$.

There was no significant association between the $A B O$ phenotypes and parasitemia $\left(X^{2}=5.47, p>0.05\right)$. Blood group A was associated with severe malaria when it was compared with individuals with blood group O (Odds ratio $=0.79, p>0.05,95 \%$ CI: 17,593-96,306) $($ Table 4). Moreover, blood group $A B$ was associated with more severe falciparum malaria when compared to blood group 0 (Odds ratio $=0.14, p>0.05$, $95 \%$ CI: $18,582-119,498)$ and also there was a significant difference in severity of malaria between blood group $O$ and blood group $B$ (Odds ratio $=1.28, \mathrm{p}>0.05,95 \% \mathrm{CI}: 11,332-82,716)($ Table 4$)$

\section{Discussion}

The $A B O$ blood group system in Ghanaians and other West Africans from earlier studies have given the prevalence of blood group $O$ as $50 \%$, $A B$ about 3\%, and the remainder being groups $A$ and $B$ in about equal proportions with $B$ being slightly more than $A$ [31-34]. The same observation was made in this study except that the $A B$ group was higher than reported frequencies.

Studies conducted show that parasitized erythrocytes form rosettes more readily with red blood cells of either $A, B$ or $A B$ groups than with those belonging to blood group $0,[3,35,37]$ and that, in Zimbabwe, blood group A was associated with both lower hemoglobin levels and severe central nervous system malaria with coma [4]. In spite of the fact that these phenomena might provoke an association of $A B O$ blood groups and severe falciparum malaria infection, the results presented in this study do not permit the rejection of the null hypothesis that the $A B O$ blood group system is not associated with $P$. falciparum malaria infection.

The mechanism by which blood group $O$ confers the somewhat protective effect against severe malaria compared to blood groups $A$, $B$, or $A B$ is not totally understood as indicated by studies reviewed [38]. However, a logical explanation may be provided on the basis of the rosette formation. Evidence from some studies reviewed clearly established that parasitized erythrocytes form rosettes more readily with $R B C s$ of either $A$, $B$, or $A B$ blood groups than with those belonging to blood group $\mathrm{O}$ [3,35-37]. Also, it is well established that this parasite-triggered RBC rosette formation is associated with the development of cerebral malaria $[20,25]$.

In this study, there was no significant association between the ABO blood group system and $P$. falciparum malaria infection, as observed in Nigeria among children with severe malaria $[39,40]$. It was observed that the non-O blood group individuals tend to have more severe falciparum malaria than the blood group 0 individuals. Moreover, in the severe malaria group, it was noted that the lowest mean haemoglobin occurred in the blood group A individuals, as observed in a trial in Zimbabwe [4]. The two cases of very high risk of mortality (more than $10 \%$ of red blood cells parasitized or more than 500,000 parasites/ $\mu$ l) were observed in individuals with blood group $O$ whereas the percentage severity of falciparum malaria was highest with the $A B$ phenotypes. And this seems to be significant because the percentage (11.5\%) was higher than the frequency distribution (4.2\%) among the children assessed.

\section{Conclusion}

This study has shown that non-O blood group children are more prone to severe malaria caused by $P$. falciparum than the group 0 children. Therefore, identifying ABO phenotypes could help to detect those children at high risk for malaria. 


\section{Acknowledgments}

The authors acknowledge the Research and Ethical Review Committee of the School of Allied Health Sciences and the Department of Child Health Laboratory for approval. Also, we thank Mr Emmanuel Adongo and the staff of the Department of Child Health Laboratory.

\section{Competing interests}

Authors declared they have no competing interests.

\section{Authors' contributions}

All authors made substantial contributions to conception and design, acquisition of data, analysis and interpretation of data and were involved in drafting the manuscript and revising it critically for important intellectual content; and gave final approval of the version to be published.

\section{Tables}

Table 1: Age distribution, haemoglobin concentration, total white cell count (WBC) and ABO blood groups distribution among the subjects in the study at the Department of Child Health, Korle-Bu Teaching Hospital, Ghana

Table 2: ABO blood groups and distribution of $P$. falciparum malaria based on severity of parasitemia among the subjects in the study at the Department of Child Health, Korle-Bu Teaching Hospital, Ghana

Table 3: Mean total white cell count (WBC) and haemaglobin concentration distribution among the children in relation to the severity of malaria parasitemia, Korle-Bu Teaching Hospital, Ghana

Table 4: The determination of how significant the difference between the $O$ blood group and the non-O blood groups ( $A, B$ and $A B$ ) in the distribution of the severity of the P. falciparum malaria in the children at the Department of Child Health, Korle-Bu Teaching Hospital, Ghana

\section{References}

1. Greenwell P. Blood group antigens: molecules seeking a function?. Glycoconjugate Journal. 1997; 14(2):159-173. This article on PubMed

2. Fischer PR, Boone P. Short report: severe malaria associated with blood group. American Journal of Tropical Medicine and Hygiene. 1998; 58:122-3. This article on PubMed

3. Barragan A, Klremsssner PG, Wahlgre M, Carlson J. Blood group A antigen is a co-receptor in Plasmodium falciparum rosetting. Infection and Immunity. 2000; 68:2971-5. This article on PubMed

4. Pathirana SL, Alles HK, Bandara S, Phone-Kyaw M, Perera MK, Wickremasinghe AR, Mendis KN, Handunnetti SM. ABO-blood-group types and protection against severe, Plasmodium falciparum malaria. Ann Trop Med Parasitol. 2005; 99(2):119-24. This article on PubMed

5. Wikipedia. Blood groups. Available at www.wikipedia.com/en/ABObloodgroups/. Accessed 15 May 2011

6. Fortin A, Stevenson MM, Gros P. Susceptibility to malaria as a complex trait: big pressure from a tiny creature. Hum Mol Genet. 2002; 11(20):2469-78. This article on PubMed

7. Min-Oo G, Gros P. Erythrocyte variants and the nature of their malaria protective effect. Cell Microbiol. 2005; 7(6):753-63. This article on PubMed

8. Pasvol G. How many pathways for invasion of the red blood cell by the malaria parasite?. Trends Parasitol. 2003; 19(10):430-2. This article on PubMed

9. World Health Organization Expert Committee Report on Malaria: 20th Report; 2000. World Health Organization, Geneva, Switzerland

10. Snow RW et al. Estimating mortality, morbidity and disability due to malaria among Africa's non-pregnant population. Bulletin of the World Health Organization. 1999; 77(8):624-40. This article on PubMed

11. World Health Organization, Global Malaria Programme - Roll Back Malaria. This article on PubMed

12. History of Plasmodium Parasites. Available at http://www.wehi.edu.au/MalDB-www/intro.html. Accessed 15 may 2011 
13. W E Paul and R A Seder.Lymphocyte responses and cytokines. Cell. 1994 Jan 28;76(2):241-51. This article on PubMed

14. J Currier, J Saltabongkot, M F Good.'Natural' T cells responsive to malaria: evidence implicating immunological cross-reactivity in the maintenance of TCR alpha beta+ malaria-specific responses from non-exposed donors. Int Immunol. 1992 Sep;4(9):985-94. This article on PubMed

15. J Langhorne, M Goodner, C Behr, P Dubois.Is there a role for gamma delta T cells in malaria?Immunol Today. 1992 Aug;13(8):298-300. This article on PubMed

16. Miller LH, Baruch DI, Marsh K, Doumbo OK. The pathogenic basis of malaria. Nature. 2002; 415:673-679. This article on PubMed

17. Sherman IW, Eda S, Winograd E. Cytoadherence and sequestration in Plasmodium falciparum: defining the ties that bind. Microbes and Infection. 2003; 5:897-909. This article on PubMed

18. Ho M, Hickey MH, Murray AG, Andonegui G, Kubes P. Visualization of Plasmodium falciparum-endothelium interactions in human microvasculature: mimicry of leukocyte recruitment. J Exp Med. 2000; 192:1205-1210. This article on PubMed

19. Fernandez V, Treutiger CJ, Nash GB, Wahlgren M. Multiple adhesive phenotypes linked to rosetting binding of erythrocytes in Plasmodium falciparum malaria. Infect Immun. 1998; 66:2969-2975. This article on PubMed

20. Chotivanich KT, Udomsangpetch R, Pipitaporn B, Angus B, Suputtamongkol Y,Pukrittayakamee S, White NJ. Rosetting characteristics of uninfected erythrocytes from healthy individuals and malaria patients. Ann Trop Med Parasitol. 1998; 92: 45-56. This article on PubMed

21. Pain A, Ferguson DJP, Kai O, Urban BC, Lowe B, Marsh K, Roberts DJ. Platelet-mediated clumping of Plasmodium falciparum-infected erythrocytes is a common adhesive phenotype and is associated with severe malaria. Proc Natl Acad Sci U S A. 2001 Feb 13;98(4):180510. This article on PubMed

22. Serghides L, Smith TG, Patel SN, Kain KC. CD36 and malaria: friends or foes?. Trends Parasitol. 2003; 19:461-469. This article on PubMed

23. Carlson J, Helmby H, Hill AVS, Brewster D, Greenwood BM, Wahlgren M. Human cerebral malaria: association with erythrocyte rosetting and lack of anti-rosetting antibodies. Lancet. 1990; 336:1457-1460. This article on PubMed

24. Ho M, Davis TME, Silamut K, Bunnang D, White NJ. Rosette formation of Plasmodium falciparum-infected erythrocytes from patients with acute malaria. Infect Immun. 1991; 59:2135-2139. This article on PubMed

25. Treutiger CJ, Hedlund I, Helmby H, Carlson J, Jepson A, Twumasi P, Kwiatkowski D, Greenwood BM, Wahlgren M. Rosette formation in Plasmodium falciparum isolates and antirosette activity of sera from Gambians with cerebral or uncomplicated malaria. Am J Trop Med Hyg. 1992; 46:503-510. This article on PubMed

26. Rowe A, Obeiro J, Newbold CI, Marsh K. Plasmodium falciparum rosetting is associated with malaria severity in Kenya. Infect Immun. 1995; 63: 2323-2326. This article on PubMed

27. Chen Q, Heddini A, Barragan A, Fernandex V, Pearce SF, Wahlgren M. The semiconserved head structure of Plasmodium falciparum erythrocyte membrane protein 1 mediates binding to multiple independent host receptors. J Exp Med. 2000; 192:1-9. This article on PubMed

28. Chen Q, Schlichtherle M, Wahlgren M. Molecular aspects of severe malaria. Clin Micro Rev. 2000; 13:439-450. This article on PubMed

29. Perlmann P, Troye-Blomberg M (eds). Malaria Immunology. Chem Immunol Basel, Karger. 2002; 80:163-187

30. Cheesbrough M. District Laboratory Practice in Tropical Countries, Part 2, Low Price Edition 2000, Cambridge University Press

31. Worlledge S, Ognemudia SE, Thomas CO, Ikoku BN, Luzatto L. Blood group antigens and antibodies in Nigeria. Ann Trop Med Parasitol. 1974; 68: 249-264. This article on PubMed

32. Acquaye JK. Red cell antigens in Ewes of Ghana. Ghana Med J. 1992; 26:438-447

33. Dacie V and Lewis SM. Practical haematology. 6th ed. Churchill Livingstone Edinburgh, 1981

34. Armattoe REG, Ikin EG and Mourant AB. The ABO, Rh and MN blood groups of the Ewe and Ashanti of Gold Coast. West Afr Med J. 1953; 2: 89-93

35. Udomsangpetch R, Wählin B, Carlson J, Berzins K, Torii M, Aikawa M, Perlmann P, Wahlgren M. Plasmodium falciparum-infected erythrocytes from spontaneous erythrocyte rosettes. J Exp Med. 1989; 169:1835-1840. This article on PubMed 
36. Udomsangpetch R, Todd J, Carlson J, Greenwood BM. The effects of haemoglobin genotype and ABO blood group on the formation of rosettes by Plasmodium falciparum-infected red blood cells. Am J Trop Med Hyg. 1993 Feb;48(2):149-53. This article on PubMed

37. Carlson J, Wahlgren M. Plasmodium falciparum erythrocyte rosetting is mediated by promiscuous lectin-like interactions. J Exp Med. 1992; 176:1311-1317. This article on PubMed

38. Uneke $\mathrm{CJ}$. Plasmodium falciparum malaria and ABO blood group: is there any relationship?. Parasitol Res. 2007; 100:759-765. This article on PubMed

39. Martin SK, Miller LH, Hicks CU, David-West A, Ugbode C, Deane M. Frequency of blood group antigens in Nigerians children with falciparum malaria. Trans R Soc Trop Med Hyg. 1979; 73:216-218. This article on PubMed

40. Kassim OO, and Ejezie GC. ABO blood groups in malaria and schistosomiasis haematobium. Acta Trop. 1982; 39:179-184. This article on PubMed

Table 1: Age distribution, haemoglobin concentration, total white cell count (WBC) and ABO blood groups distribution among the subjects in the study at the Department of Child Health, Korle-Bu Teaching Hospital, Ghana

\begin{tabular}{|c|c|c|c|c|c|c|c|c|}
\hline & & & & & \multicolumn{4}{|c|}{ Blood groups } \\
\hline Gender & Number & Mean Age (years) & Mean Hb (g/dl) & Mean WBC (x 109/I) & $\mathbf{A}$ & B & $\overline{A B}$ & 0 \\
\hline Male & $71(59 \%)$ & $3.6 \pm 2.8$ & $7.9 \pm 2.6$ & $10.8 \pm 5.6$ & 14 & 18 & 4 & 35 \\
\hline Female & $50(41 \%)$ & $3.3 \pm 2.8$ & $7.3 \pm 2.6$ & $11.5 \pm 4.8$ & 10 & 14 & 1 & 25 \\
\hline
\end{tabular}

Table 2: ABO blood groups and distribution of $P$. falciparum malaria based on severity of parasitemia among the subjects in the study at the Department of Child Health, Korle-Bu Teaching Hospital, Ghana

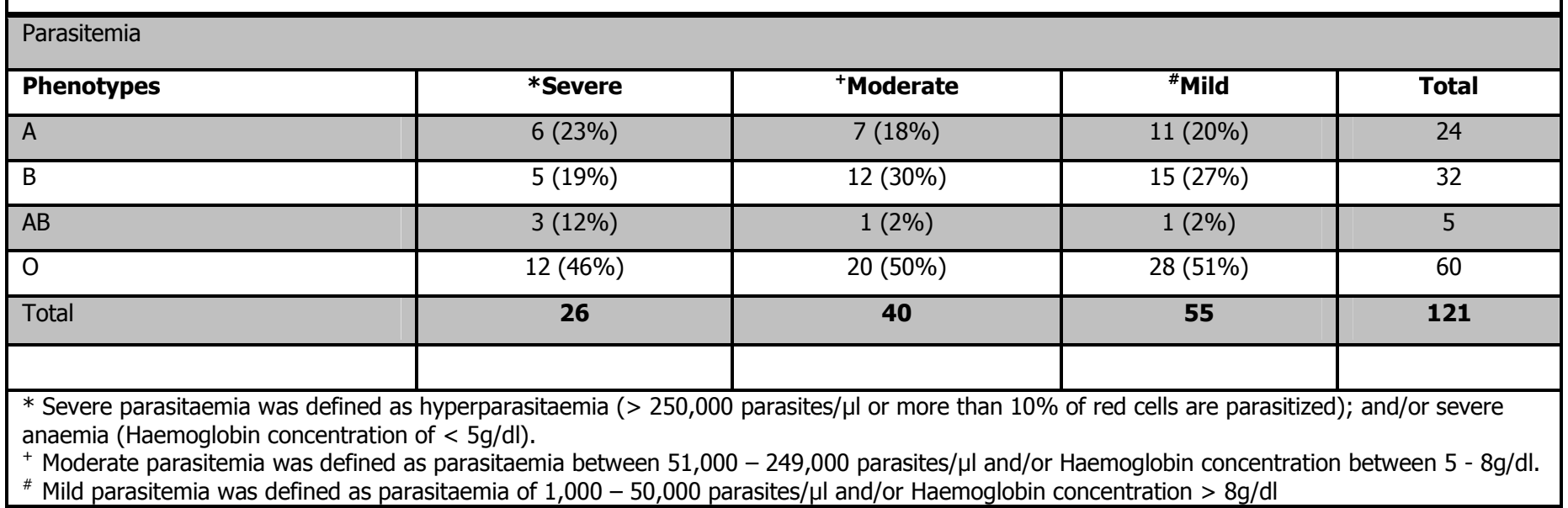




\begin{tabular}{|l|c|c|}
\hline \multicolumn{2}{|l|}{ Table 3: Mean total white cell count (WBC) and haemaglobin concentration distribution among the children in relation to the } \\
severity of malaria parasitemia, Korle-Bu Teaching Hospital, Ghana \\
\hline Severity of malaria parasitemia & WBC \pm SD (x10 $/$ /) & $9.9 \pm 1.3$ \\
\hline Mild & $11.5 \pm 6.1$ & $6.4 \pm 0.8$ \\
\hline Moderate & $11.4 \pm 6.2$ & $4.5 \pm 1.7$ \\
\hline Severe & $11.5 \pm 4.5$ & \\
\hline
\end{tabular}

Table 4: The determination of how significant the difference between the $O$ blood group and the non-O blood groups $(A, B$ and $A B)$ in the distribution of the severity of the P. falciparum malaria in the children at the Department of Child Health, Korle-Bu Teaching Hospital, Ghana

\begin{tabular}{|c|c|c|c|c|c|}
\hline \multicolumn{6}{|c|}{ Parasitemia } \\
\hline & $\begin{array}{c}\text { Severe \& Moderate } \\
\text { Parasitemia }\end{array}$ & $\begin{array}{c}\text { Mild } \\
\text { Parasitemia }\end{array}$ & Odds ratio ( 0 versus Non- 0 ) & P-value & $\begin{array}{c}\text { Difference in } \\
\text { Severity }\end{array}$ \\
\hline A & 13 & 11 & 0. $97,95 \%$ C.I. $(17,593-96,306)$ & 0.5 & Not Significant \\
\hline $\bar{B}$ & 17 & 15 & $1.01,95 \%$ C.I. $(11,332-82,716)$ & 0.7 & Not Significant \\
\hline$\overline{A B}$ & 4 & 1 & $0.29,95 \%$ C.I. $(18,582-119,498)$ & 0.5 & Not Significant \\
\hline $\mathrm{O}$ & 32 & 28 & $\mathrm{~N} / \mathrm{A}$ & $\mathrm{N} / \mathrm{A}$ & $\mathrm{N} / \mathrm{A}$ \\
\hline
\end{tabular}

